\title{
Management Accounting Systems Change And Sub-Unit Performance: The Moderating Effects Of Perceived Environmental Uncertainty
}

\author{
Alfred E. Seaman, (Email: seamana@unimail.cis.mcmaster.ca), Mc Master University, Canada
} John J. Williams, Singapore Management University, Singapore

\begin{abstract}
This study reports the findings of an empirical study that investigated changes in five major management accounting system components (MASCs) and their linkages to the external environment and managerial performance. Responses from 116 Singaporean CFOs located in small- to medium-sized manufacturing and industrial firms were used to test the primary hypothesis that perceived environmental uncertainty (PEU) moderates the MASCs changeperformance relationship. Positive evidence permitted subsequent analysis showing that different configurations of MASCs change enhanced CFO performance under both low and high levels of PEU. Further statistical evidence demonstrated that it is changes in specific components, matched with specific levels of PEU, which is responsible for improved performance. When PEU is low, a 'defensive' pattern of MASCs change emerged, dominated by more importance placed on emphasizing planning systems changes and de-emphasizing costing systems changes. Under conditions of high PEU, an 'aggressive' pattern of change was revealed, characterized by more primacy given to emphasizing novel changes to decision making systems while de-emphasizing changes to reward and bonus systems.
\end{abstract}

\section{INTRODUCTION}

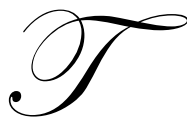

he phenomenon of change in management accounting systems has sparked increasing interest among accounting scholars. Reviews of recent literature reveal discussions that address theories of why and how such change is unfolding, the management of this process, epistemological and political issues, and the functional logic underpinning the change process (e.g. Burns and Vaivio; 2001; Quattrone and Hopper; 2001). Empirical studies are equally diverse, spanning a multitude of national settings, business sectors and research methodologies (e.g. Granlund and Lukka, 1998; Luther and Longden, 2001). Some works (including cases and large surveys) concentrate on individual management accounting system components, such as ABC (Gosselin, 1997), with the focus on impediments or barriers to successful implementation. Other studies apply a contingency perspective in the search for determinants, catalysts or motivators of a contextual or structural nature, which are thought to influence changes in a set of component management accounting systems (Innes and Mitchell, 1990; Libby and Waterhouse, 1996; Laitinen, 2001; Williams and Seaman, 2001). On balance, results have been fragmented and difficult to integrate.

Noticeably absent in the empirical literature are studies of the relationship between changes in management accounting systems and performance at the strategic level, where systems changes are initiated. In highly centralized organizations, for example, the CFO is likely to have the requisite power, authority, and knowledge to design the appropriate firm-wide management accounting information system. This 'logic of change' perspective "grants a key role to the motivated actors who initiate and take responsibility for transformations in the management accounting craft and has its place in our understanding of management accounting change" (Burns and Vaivio; 2001, p. 394). 
The familiar goal congruence concept (Horngren and Sundem, 1990) implies that changes in the accounting information system will be undertaken so as to benefit both organizational performance and the CFO's managerial performance.

Kaplan (1985) suggested that information signals from the external environment will have a simple causeeffect relationship on the different types of management accounting changes that emerge in firms. Theory and evidence from the organization theory literature, however, view this process differently, and it generally uses the term uncertainty with reference to environmental effects. Uncertainty is not anchored in an objective physical reality but, instead, constitutes a behavioral environment that is perceived and reacted to by individuals (Dill, 1962; Weick, 1969; Galbraith, 1973; Downey, 1974). Thus, perceived environmental uncertainty (PEU) is a strategic level variable (Tymon, Stout and Shaw, 1998) that is expected to have a moderating influence on the firm's information system design and, by extension, to the number of changes to management accounting system components (MASCs) that represent the overall management accounting and control system ${ }^{1}$.

One reason for studying the MASCs change-performance relationship within the strategic context of PEU is the potential to discover different patterns of management accounting changes that are compatible with variations in the external environment. The strategic management literature suggests that firms structure and use information processes with different characteristics given variations in strategic level variables (Miles and Snow, 1978; Miller, 1989). Moreover, empirical evidence also suggests that performance is enhanced when information systems are designed to fit strategic level variables (Miller, 1989; Rogers, Miller and Judge, 1999). Therefore, this implies that firms must design different types of component configurations (and, hence, corresponding changes) in their management accounting systems to match different levels of environmental uncertainty for better performance.

The purpose of this paper is to report results of an exploratory empirical study that examines the moderating effects of PEU on the MASCs change-performance relationship at the strategic level of the firm. The focus is not on the management of change internal to the firm but rather on the changes to different components that comprise the management accounting system at the organizational level. A sample consisting of CFO responses from 116 Singaporean manufacturing and industrial firms provided data for the model. The next section develops background literature leading to a statement of the primary hypothesis under investigation. Previous theory and evidence pertaining specifically to the issue of management accounting change is reviewed first followed by literature that unveils the critical importance of PEU in the information linkage between management accounting systems change and performance. Qualifying conditions that impact the research design are then considered.

The method and research design section carefully describes the sample and the choices confronted in the measurement of all variables. In addition, the three-stage analysis utilized to arrive at a direct test of the primary hypothesis is explained in detail, together with the choice of statistical methods and stated expectations concerning the outcomes at each stage. In the results section, descriptive statistics and correlations are provided for all variables in addition to the findings of the simple linear regression models run in stages 1 and 2 . The use, and the results of, Moderated Regression Analysis applied to the full interaction model in stage 3 are explained and disclosed, respectively, including the F-change statistic as a direct test of the research hypothesis.

Positive confirmation of the research hypothesis indicating the significant moderating effects of PEU on the MASCs change-performance relationship presented a novel opportunity for additional analysis in stage 4, which otherwise would not have been possible. Two issues, rooted in much of the accounting contingency literature and contingency fit literature, concern the design of different types of management accounting systems under different environmental contexts, and which particular systems feature prominently in each design. Thus, two regressions are modeled for low and high levels of PEU using the SAS Mtest procedure. Comparative results are then examined along with F-test difference statistics and, collectively, they show two distinct patterns of MASCs change under low and high levels of PEU that both enhance managerial performance. Finally, a series of conclusions, limitations, and subsequent research opportunities close out the last section of the paper. 


\section{BACKGROUND AND HYPOTHESIS DEVELOPMENT}

\section{Prior Literature}

A significant literature exists on a variety of techniques used by management accountants, the adaptability of management accounting to organizational, technological, and competitive changes, and the nature of management accounting in various international contexts. Only a few studies, though, have examined changes in management accounting systems at the organization level using survey data, and are thus relevant to the present study. Focusing on a Canadian sample of manufacturing firms, Libby and Waterhouse (1996) developed a dependent management accounting and control systems (MACS) change variable that included changes to 23 sub-systems partitioned into five categories (see Appendix A) to analyze the impact of size, intensity of competition, decentralization, and the capacity to learn as major determinants of change. Organizational capacity to learn was the only statistically significant predictor of overall MACS change and the decision-making change component.

Williams and Seaman (2001) replicated the Libby and Waterhouse (1996) study using a sample of Singaporean firms. They utilized Hofstede's $(1980,1985,1991)$ national culture arguments for a high 'power distance' society to substitute centralization for decentralization. The former emerged as the most significant predictor of increases in MACS change for firms in the manufacturing and industrial sectors, but not in the service sector. A component analysis revealed the importance of different determinants across the three economic sectors, suggesting that the external environment may interact with different types of changes in the MACS components.

Laitinen (2001) concentrated on a sample of small Finnish technology firms, partitioning management accounting changes into four classes. These classes included the use of managerial calculations (15 systems), cost accounting ( 9 systems), management control ( 8 systems), and performance measurement (5 hierarchical systems). Change was measured on a 5-point scale across each class and total systems change was determined by summation over all classes. Based on earlier work of Innes and Mitchell (1990); Gosselin (1997), and Berry (1998), four strategic content types of companies were identified along with a set of contextual and organizational variables for each type, determined by an expectation model using Simon's (1957) adaptive organism framework. Laitinen concluded that "Each type must adapt to a given environment ..." via a different configuration, including the composition of individual management accounting changes (2001, p. 538). Moreover, regression results of main effects for 12 contextual and organizational variables pointed to the 'level of competition' as the only significant determinant of change. Finally, two out of the four strategic content types analyzed showed no significant association with management accounting changes.

Despite the several positive relationships uncovered in these studies, the overall results are weak and inconclusive. In each study, some measure of change in management accounting systems is modeled as the dependent variable, thus ignoring consequent performance outcomes. Also, virtually all of the contextual variables identified are analyzed for main effects on the dependent variable, thereby omitting potentially important interaction effects that form the cornerstone of the contingency 'fit' literature (Drazin and Van de Ven, 1985; Gresov, 1989). In a unique approach, Williams and Seaman (2002) address the former concern by treating MACS change as an independent processual variable that influences organizational outcomes. Deploying a path analytic framework modeled after Kren (1992), MACS change was found to positively influence performance, not directly, but indirectly through supplying managerial relevant information, with slightly stronger effects under the moderating conditions of high task difficulty and high task variability. Unlike the studies reviewed above, however, components of the MACS change variable were not examined.

\section{PEU As An Antecedent Link In The MASC-Performance Relationship}

The management accounting system can be depicted as a composite set of sub-systems, or components, which forms the central platform of the organization's information-processing system. The literature has tended to portray these system components as mechanisms that deliver information-processing capacity for decision making, ultimately to enhance performance outcomes (Demski and Feltham, 1976; Baiman and Demski, 1980; Tiessen and Waterhouse, 1983; Horngren and Sundem, 1990; Institute of Management Accountants, 1997). Viewing management 
accounting changes as part of the informational support process in the firm readily appeals to structural contingency theory.

In this perspective, an organization's environment is viewed as a critical determinant of its structural arrangement (Burns and Stalker, 1961; Hall, 1962; Lawrence and Lorsch, 1967; Hage and Aiken, 1969; Thompson, 1967; Child, 1972). In this framework, however, the effective structuring of particular managerial processes and activities depends on the appropriate co-alignment with particular environments (Pugh, Hickson, Hinings, and Turner, 1968, 1969; Waterhouse and Tiessen, 1978). Galbraith (1973; 1977) extended this framework and developed a contingency perspective pinned on the correct matching of information and environmental uncertainty (Chapman, 1997). Briefly stated, firms experiencing changing external environments need different information-processing designs to support alternative decision-making needs and, hence, performance goals.

In this study, the PEU model developed in the accounting literature by Tymon et al. (1998) provides the strategic linkage between environmental uncertainty and the MASCs change-performance relationship that is called for in the contingency fit literature (Tushman and Nadler, 1978; Drazin and Van de Ven, 1985; Gresov, Drazin and Van de Ven, 1989). The model posits that top management perceptions of the external environment impact the organization's strategic decisions, which in turn affect design decisions encompassing organizational structure and control systems. The latter then influence the individual level, including performance, and this entire linkage ultimately impacts the firm's performance.

Tymon et al. (1998) identify four elements that characterize the role of PEU as a strategic construct. First, the organization's external environment is the source of uncertainty. However, specific external referents, such as the competitiveness of prices, promotion, distribution, product quality, and product variety, are deemed to be essential to the correct operationalization of the PEU construct. Secondly, the inability of top managers to specify precisely how these elements will interact with the firm's internal processes means the external environment is shrouded in uncertainty. Thirdly, it is the de facto perceptions of these external elements that influence strategic decision making in the context of altering the organization's information structure. Finally, the relevant perceptions about the environmental uncertainty facing the firm emanate from top managers, thus fixing the strategic orientation at the pinnacle of the organization.

Operationalizing the PEU construct, however, has generated controversy in the literature. Tymon et al. (1998) categorically dismiss claimed PEU studies that have adopted Duncan's (1972) measure because of confounding internal and external environmental referents in the scale (e.g. Ferris, 1982; Chenhall and Morris, 1986; Gregson, Wendell and Aono, 1994). Instead, they advocate using either of the scales developed by Khandwalla (1972) or Miles and Snow (1978), which incorporate only external environmental referents. Khandwalla's (1972) measure required responses on the intensity of competition pertaining to five external referents and it is considered to be extremely similar to the Miles and Snow (1978) measure.

Several studies have successfully used the PEU construct to examine management controls (Khandwalla, 1972), information system characteristics (Gordon and Narayanan, 1984), and managerial performance (Gul, 1991; Gul and Chia, 1994). Building on this evidence as well as theoretical contingency arguments provides strong support to reject the universalistic view that there is a direct association between PEU and managerial performance, or between MASCs change and performance. Instead, it is anticipated that PEU will have an interaction effect on MASCs change to positively influence performance, and it is this moderating effect of PEU that is primarily explored in the present study. Specifically, the following research hypothesis is tested ${ }^{2}$ :

H1: The relationship between change in management accounting system components and managerial performance will depend upon the moderating effects of low and high levels of perceived environmental uncertainty. 


\section{Qualifying Conditions In The Research Design}

Theory and evidence point to a contingency relationship between PEU and organizational structure. Early contingency theory literature (Pugh, Hickson, Hinnings and Turner, 1968, 1969; Child, 1972; Waterhouse and Tiessen, 1978) asserted that centralized structures are designed by administrators when there is less uncertainty in the external environment. Subsequent empirical evidence confirmed this argument (Khandwalla, 1972; Gordon and Miller, 1976; Gordon and Narayanan, 1984). More recently, and in the context of changes in management accounting systems, Williams and Seaman (2001) found centralization to be a significant predictor of MACS change in a sample of Singaporean firms. However, in related work (Canadian and Finnish survey samples, respectively), neither Libby and Waterhouse (1996) nor Laitinen (2001) found a connection between changes in management accounting and concentration of authority.

Williams and Seaman (2001) reasoned that certain aspects of Hofstede's (1980) national culture taxonomy, power distance in particular, may have a dominant impact on the organizational structure of Singaporean companies. Several researchers (Chow, Shields and Chan, 1991; Harrison, 1992; O'Conner, 1995) have provided convincing evidence to support the high 'power distance' status associated with Singaporean companies. Signature features of this particular cultural dimension include respect for authority and hierarchical dominance, acceptance of unequal power, abstinence from lower level consultation and negotiation, and manifestation of centralized leadership. These same studies essentially support the conclusion that "decentralization is not congruent with the dominant features of the more centralized authority structures that are expected to prevail in the Singaporean context (Williams and Seaman, 2001, p. 447).

A related issue in the present study is the potential effect of different industry types on the relationship stated in hypothesis H1. There have been several results (Fitzgerald, Johnston, Brignall, Silvestro and Voss, 1991; Shields, 1998; Sharma, 2002) suggesting that the nature and use of management accounting systems differ across industry sectors, most commonly manufacturing versus services. Sharma (2002) argued that firms in the hotel industry face more complex and uncertain environments and, accordingly, appear to decentralize to cope with the demands on the accounting control system. But the empirical findings specifically associated with changes in management accounting have been mixed. Both Luther and Longden (2001) and Laitinen (2001) reported no relationship across industry types. Williams and Seaman (2001), though, found that for service organizations only the planning component of MACS change yielded a significant regression result, and the coefficient for centralization, interestingly, was significantly negative. To control for structural consistency, therefore, firms in the service sector were not included in the present study.

\section{METHOD AND RESEARCH DESIGN}

\section{Sample}

Initially, 10 small- to medium-sized firms were selected from each of the 18 four-digit industry codes reported in the Dunn and Bradstreet's (1998) Directory of Singaporean Companies, excluding the banking, utilities, and other service sectors. A letter was sent to the CFO, or controller, of each firm specifying the study's nature and purpose. These executives were targeted for two reasons: (1) their superior professional knowledge surrounding the status and evolution of the firm's management accounting control sub-systems; and (2) their empowerment role in governing and coordinating firm-wide information flows. Subsequent phone contact yielded appointments with 147 organizations to authenticate the researchers' identities, to review the research instruments and instructions, to verify the hierarchical position of potential respondents, and to ensure that the firm was Singaporean-owned. All CFOs had responsibility over the accounting systems generating internal and external financial and managerial information. Self-addressed stamped envelopes were attached to each set of questionnaires to secure anonymity. The questionnaire measured changes in the management accounting system, PEU, and performance.

CFO responses were received from 126 organizations. Seven were deleted because they indicated less than three years of service in their present position while three were incomplete or had no variance across questionnaire items. These filters produced a final usable sample of 116 firms, or a 64.4 per cent response rate for the initial contact 
sample and a 78.9 per cent response rate for firms visited. Response and non-response biases were not evident ${ }^{3}$. Respondents had been employed by their respective organizations for an average of 10.4 years and had held their current positions for 5.3 years on average. As expected, firms were of smaller size based on the number of employees ${ }^{4}$.

\section{Measurement Of Variables}

The independent variables were measured following the procedures initially developed by Libby and Waterhouse (1996) and subsequently used by Williams and Seaman (2001). Changes to 23 possible management accounting systems (see Appendix A) were calculated for each firm and then partitioned into five components, namely, planning (PLAN), controlling (CON), costing (COST), directing (DIR), and decision making (DM). These changes applied to a 33-month time horizon that began January 1996, as stated in the questionnaire ${ }^{5}$. The month of January was chosen to coincide with the start of a new fiscal year for each firm. Also, an earlier commencement date could have compromised respondents' recollection of management accounting changes occurring within the organization.

PEU was measured using the competitive pressure scale originally developed by Khandwalla $(1972,1977)^{6}$. Respondents were asked for their assessment of the intensity of competition pertaining to five elements in the external environment: raw materials, technical personnel, selling and distribution, quality and variety of products, and price. Each item was rated on a fully anchored Likert scale ranging from 1 (far below average intensity) to 5 (far above average intensity) and summed to generate an overall score for each firm. The Cronbach (1951) alpha statistic was 0.78 for this measure, which satisfies Nunnally's (1967) inter-item reliability standard for exploratory research. Factor analysis produced one factor with an eigenvalue greater than 1 that accounted for 72 per cent of the total variance, thus supporting the uni-dimensional structure of the scale. The total PEU score was dichotomized at its median value to create two categorical variables for testing the research hypothesis H1. A dummy variable was coded either zero or one for low PEU and high PEU, respectively.

Managerial performance was measured utilizing a self-rating instrument because anonymity was guaranteed and superior-ratings were not easily obtainable. CFOs were asked to evaluate their overall performance in terms of effectively administering their functional role on a seven-point scale anchored by "performance is barely satisfactory" (1) to "performance is extremely good" (7). This measure has been used in other behavioral accounting research (Chenhall and Brownell, 1988), notwithstanding concerns over leniency bias (Heneman, 1974) and common-method bias (Prien and Liske, 1962) ${ }^{7}$. The accounting literature has debated these concerns at length (e.g. Brownell and McInnes, 1986; Brownell and Dunk, 1991; Frucot and Shearon, 1991). Brownell and McInnes (1986) argued that, even if leniency does exit, results will be unaffected if there is no systematic leniency in the variables modeled, which seems most likely in the present study. However, the inducement of higher correlations (i.e. common-method bias) between changes in the MACS components and performance is certainly a possibility but it is extremely unlikely to systematically affect the way PEU is measured and the calculation of the interaction variables.

\section{Analysis}

To ascertain whether any significant main or interaction effects were present in the proposed model, the analysis proceeded in three stages before arriving at a direct test of hypothesis H1. In stage 1, multiple linear regression analysis for the entire sample was used to investigate the association between performance and the five change components without controlling for PEU:

$\mathrm{PERF}=\alpha+\beta_{1} \mathrm{PLAN}+\beta_{2} \mathrm{CON}+\beta_{3} \mathrm{COST}+\beta_{4} \mathrm{DIR}+\beta_{5} \mathrm{DM}+\epsilon$

where PERF $=$ managerial performance, PLAN $=$ planning component changes, $\mathrm{CON}=$ controlling component changes, COST $=$ costing component changes, DIR $=$ directing component changes, $\mathrm{DM}=$ decision making component changes. An insignificant finding would provide evidence of no direct main effects of the change components on performance. 
Stage 2 analyzed the same set of independent variables included in Eq. (1) but added PEU as a sixth independent variable:

$\mathrm{PERF}=\alpha+\beta_{1} \mathrm{PLAN}+\beta_{2} \mathrm{CON}+\beta_{3} \mathrm{COST}+\beta_{4} \mathrm{DIR}+\beta_{5} \mathrm{DM}+\beta_{6} \mathrm{PEU}+\epsilon$

where PEU = a dummy variable equal to zero if PEU is low and one if PEU is high, and all other variables are as defined in Eq. (1). The reduced equation presented in Eq. (2) is intended to examine the direct effect of PEU on the dependent performance variable. Again, an insignificant finding would provide evidence of no main effect emanating from the PEU variable ${ }^{8}$.

In stage 3, Moderated Regression Analysis (MRA) was run to develop a full model that included all the independent variables from Eq. (2) plus the interactions between PEU and each of the five change components:

$\mathrm{PERF}=\alpha+\beta_{1} \mathrm{PLAN}+\beta_{2} \mathrm{CON}+\beta_{3} \mathrm{COST}+\beta_{4} \mathrm{DIR}+\beta_{5} \mathrm{DM}+\beta_{6} \mathrm{PEU}+\beta_{7}(\mathrm{PEU} \times \mathrm{PLAN})+\beta_{8}(\mathrm{PEU} \times \mathrm{CON})+$ $\beta_{9}(\mathrm{PEU} \times \mathrm{COST})+\beta_{10}(\mathrm{PEU} \times \mathrm{DIR})+\beta_{11}(\mathrm{PEU} \times \mathrm{DM})+\epsilon$

where all variables are as previously defined. The product terms in Eq. (3) represent the moderating effects of PEU on the relationship between the five component variables and performance. The full model then was evaluated against the reduced model to determine whether PEU had significant interaction effects on the independent variables. This was accomplished by examining the statistical significance of the increase in variance explained (i.e. significant increase in $\mathrm{R}^{2}$ ) when the reduced model in Eq. (2) (only main effects) was compared with the full model in Eq. (3) (main and interaction effects) $^{9}$. In conjunction with MRA, the SPSS statistical package provides an F-change statistic that tests the significant improvement in $\mathrm{R}^{2}$. A significant finding would support hypothesis $\mathrm{H} 1$.

\section{RESULTS}

\section{Descriptive Statistics}

Table I gives the means, standard deviations, theoretical, and actual ranges for all variables. The Pearson correlation matrix for the measured variables is presented in Table II. None of the independent variables are correlated with performance. In addition, PEU does not appear to be significantly correlated with either the independent variables or performance, which Shields and Shields (1999) argued is an important property associated with a true moderating variable. In line with theoretical expectations then, these statistical outcomes confirm the absence of any main effects on performance. Finally, there are some statistically weak correlations among the independent variables, but not sufficient to create any multicollinearity problems in the regression models ${ }^{10}$.

A profile of the number of changes for each independent variable in each PEU subgroup is given in Table III. The relative percentages for each change variable displayed in the last column are nearly identical to those reported in the Williams and Seaman (2001) study. Moreover, the larger number of total component changes shown for the high PEU subgroup matched expectations (Khandwalla, 1972; Tushman and Nadler, 1978; Simons, 1987). The mean PEU scores for the low and high subgroups are 13.767 and 20.134, respectively. A t-test confirmed that the two subgroups are significantly different statistically $(t=31.423 ; \mathrm{p}=0.000)$, while control checks for size $(\mathrm{t}=0.055 ; \mathrm{p}=0.815)$ and centralization $(t=0.529 ; p=0.468)$ showed no significant difference ${ }^{11}$.

\section{Regression Results For Main And Interaction Effects}

Regression results for the first three stages of the analysis are reported in columns 2, 3, and 4 of Table IV. Column 2 shows the results from fitting Eq. (1). There is no significant relation between MASCs change and performance (adjusted $\mathrm{R}^{2}=0.038 ; \mathrm{F}=1.890 ; \mathrm{p}>0.10$ ), consistent with the correlation outcomes reported in Table 2 . This confirms expectations of no direct main effects between management accounting control system components and performance. 
The results of estimating the reduced model containing PEU in Eq. (2) are reported in column 3. There is no significant main effect of PEU on performance (adjusted $\mathrm{R}^{2}=0.030 ; \mathrm{F}=1.591 ; \mathrm{p}>0.10$ ), thus further supporting the correlation results in Table II. This outcome also confirms expectations that strategic-level variables should not directly influence performance.

The results of estimating the full model represented by Eq. (3) are reported in column 4. This model specification includes the interaction terms to determine if low/high levels of PEU modify the relation between MASCs change and performance. The significant finding (adjusted $\mathrm{R}^{2}=0.116 ; \mathrm{F}=2.369 ; \mathrm{p}<0.05$ ) presents clear evidence of the moderating effect of PEU. However, to provide a direct test of hypothesis H1, the results from Eq. (2) and Eq. (3) were compared using an F-change statistic from the SPSS statistical package. The F-change statistic revealed a significant improvement in the adjusted $R^{2}(F=3.116 ; p<0.05)$, thus confirming the expected moderating effect of PEU. To justify using five component variables in the regression model, all three regression equations were re-run using one overall measure of change in MACS as the independent variable. As expected, based on the findings of Williams and Seaman (2002), no significant relationships were found.

\section{Additional Analysis}

Confirmation of hypothesis $\mathrm{H} 1$ was essential in order to further explore two important issues addressed in the accounting literature. First, does a significant relationship emerge between MASCs change and performance for both low and high levels of PEU, as implied in the contingency 'fit' literature? Secondly, if affirmative, are the five component change variables equally important, then, in each configuration? For each dependent variable from the two PEU subgroups considered simultaneously, the SAS Mtest procedure provides a test of the null hypothesis that there is no difference in the estimated regression coefficients of any independent variable across the two models (Rogers $e t$ al., 1999).

Therefore, two regression equations were estimated for low PEU and high PEU, respectively, using the five change components as independent variables and the corresponding performance outcome in each case as the dependent variable. The emergence of two significant regression results would allow the conclusion that both sets of independent change variables yield effective performance, and thus an affirmative answer to the first question. Also, a significant F-test difference statistic would allow the conclusion that different amounts of change in the MASCs contribute to effective performance in each configuration, thus answering the second question negatively.

The regression results in column 5 of Table IV (adjusted $\mathrm{R}^{2}=0.132 ; \mathrm{F}=2.894 ; \mathrm{p}<0.05$ ) and column 6 (adjusted $\mathrm{R}^{2}=0.106 ; \mathrm{F}=2.261 ; \mathrm{p}<0.05$ ) for low/high PEU, respectively, affirm the first question stated above ${ }^{12}$. Considering low PEU, emphasizing change in the planning sub-systems (i.e. significant positive coefficient) while deemphasizing change in the costing sub-systems (i.e. significant negative coefficient) influence managerial performance the most. The high PEU model indicates that performance is influenced largely through emphasizing change in the decision-making sub-systems (i.e. significant positive coefficient) and by simultaneously deemphasizing change in the directing sub-systems (i.e. significant negative coefficient).

Column 7 of Table IV shows four significant F-test differences (i.e. PLAN, $\mathrm{p}<0.01$; COST, $\mathrm{p}<0.01$; DIR, $\mathrm{p}$ $<0.01$; and DM, $\mathrm{p}<0.01$ ) when comparing the regression results for the low and high PEU subgroups. Only the controlling component exhibits no significant difference. This evidence offers a compelling reason to conclude that the configurations of changes in MASCs associated with low and high PEU, respectively, are fundamentally different and, yet, each configuration enhances performance accordingly.

Finally, the analysis and results presented above are based exclusively on measuring MACS changes as the number of reported system changes out of the 23 sub-systems included in the scale and decomposing this set according to the five categories developed by Libby and Waterhouse (1996). This procedure ignores the possible influence of existing systems within each firm. For example, an organization that changes 6 of 18 systems versus one that changes 6 of 12 systems may not have experienced the same degree of change in the information supplied by these systems. However, learning and change may possibly arise from experience and the capacity to assimilate change (Levitt and March, 1988; Cohn and Leventhal, 1990; Libby and Waterhouse, 1996). Hopwood (1987) argued 
that constituted accounting systems can propel new changes through enhanced perceptions and strategic enactment. Alternatively, these forces may inhibit, or constrain, top management action thus leading to inertia and the reinforcement of existing systems (Lorenzi, Sims and Slocum, 1981; Gray, 1990).

To explore this issue further, regression Eqs. (1), (2), and (3) were re-estimated by substituting a learning effect in place of the absolute number of changes in the MASCs. For each of the five independent variables, a ratio was calculated that incorporated the number of changes in the numerator and the number of sub-systems in use in the denominator. No statistically significant findings emerged in any of the three regressions and, hence, the analysis was truncated after completing the third stage. For the present sample of Singaporean firms, PEU does not appear to moderate the relationship between performance and the relative changes in the MASCs based on the number of existing systems in each firm.

\section{CONCLUSIONS, LIMITATIONS AND SUBSEQUENT RESEARCH}

The results in aggregate provide several distinct conclusions. First, the linkage between managerial performance and MASCs change is more clearly revealed by including the strategic moderating effects of PEU, as repeatedly condoned in the accounting contingency literature (Otley; 1980, 1999). After running the regressions in stages 1 and 2, there was no evidence to support this linkage. Abandoning the analysis at this juncture would have led to the false conclusion, contrary to theory, that changes in the formal management accounting sub-systems and CFOs perceptions of uncertainty in the external environment are unimportant in relation to managerial performance.

Secondly, unequivocal evidence emerged from stage 3 of the analysis supporting the moderating effects of PEU on the MASCs change-performance relationship. The full model incorporating the interaction effects of PEU showed a significant increase in the variance explained, which was validated by a significant F-change statistic. Simply stated, PEU is a crucial antecedent variable in the linkage, precisely as Tymon et al. (1998) modeled it.

The additional analysis produced a third conclusion. Singaporean CFOs experiencing different levels of environmental uncertainty that overarch the change process emphasize alternative components in their firms' management accounting systems. Under conditions of low PEU, successful CFOs seem to concentrate on the realignment, or change, in their planning systems while refraining from tampering too much with efficient costing systems that are in place. In the overall change design, controlling, directing, and decision making sub-systems do not seem to require substantial remaking. Conversely, successful CFOs that experience high levels of PEU respond by emphasizing changes to their decision making sub-systems while deemphasizing changes to their directing subsystems.

The comparative outcomes in the low/high PEU profiles uncovered by the F-test difference statistic lead to a related conclusion. Four of the five independent change variables are statistically different and, thus, two 'gestalts' appear to characterize the package of managerial accounting changes designed by this sample of Singaporean CFOs. The 'defensive' pattern of changes observed under low PEU reflects a rational maintenance approach to gathering and supplying requisite information throughout the firm. This corresponding evidence from the analysis in stage 4 is largely congruent with other research literature that upholds the merits of standardization and the maintenance of costefficient operations for managers/firms facing highly predictable external business environments (Thompson, 1967; Kwandalla, 1972; Gordon and Miller, 1976; Miles and Snow; 1978; Porter, 1980). Under these circumstances, planning mechanisms and budgets become effective control devices (Chenhall and Morris, 1986), quantitative cost systems built on financial measures are preferred (Gordon and Narayanan, 1984), and less dysfunctional behavior is likely (Merchant, 1990). Thus, dynamic change in the planning component sub-systems is favored in the defensive pattern, but in conjunction with minimal change in the costing component sub-systems.

The 'aggressive' pattern found under high PEU seems to reflect a more innovative and adaptive approach to accumulating and distributing information throughout the firm. Likewise, the evidence here is consistent with that found in the empirical literature where managers/firms facing more unpredictable competitive environments report information more frequently and broadly (Gordon and Miller, 1976, Tushman and Nadler, 1978; Simons, 1987; Gul and Chia, 1994); favor qualitative-based decision making and flexible tailor-made performance measures (Simons, 
1987; Otley, 1999); and do not restructure formal evaluation and reward systems (Miles and Snow, 1978; Govindarajan, 1984; Govindarajan, 1985). Thus, dynamic change in the decision making component is favored in the aggressive pattern, but in conjunction with minimal change in the directing component sub-systems.

Only the CON variable yielded no significant F-test statistic. This variable reflects change in performance measures that span human resources, product quality, and customer satisfaction - all essential components in the 'balanced scorecard' approach to strategic management. It would appear that effective performance is garnered by CFOs in each gestalt through not compromising on needed changes in these sub-systems. Thus, controlling systems changes might be thought of as required stabilizers in the mix of managerial accounting changes to ensure better performance regardless of environment predictability.

The results of this study are certainly subject to the usual limitations of survey type research. Also, issues pertaining to the sample period, hindsight bias, and constraining the survey questionnaire to executive accounting positions may have affected the data in unknown ways. Appealing to the power distance dimension (i.e. centralization) in Hofstede's (1980) taxonomy of national culture dimensions as an indirect structural control variable (even though centralization was measured directly) necessarily limits the findings, but encourages more research of the present type at the strategic level in decentralized firms.

Although this study's findings are supported by convincing statistical evidence, a more critical assessment of the measures used, and the model, is warranted. To begin with, the amount of variance explained after running the regression model in stage 3 was disappointingly low, even though it yielded a four-fold increase in the explained variance compared to the reduced model in stage 2. Normally in regression analysis this implies missing variables, or needed refinements in measuring the independent variables. Granlund (2001, p. 155), for example, was critical of the "circular definition of accounting change" used by Libby and Waterhouse (1996) and "the ways change is measured". Indeed, partitioning a complex firm-wide management accounting system into meaningful components is a challenging endeavor, and it requires substantial attention and consolidation in future work of this kind.

The measure of managerial performance may have been problematic as well for reasons of correspondence. Probably not all CFOs in the sample were responsible for exactly the same work tasks and, most certainly, their individual performance was a function of other work dimensions than simply administering and implementing changes to the accounting information system. Without doubt, valid and reliable dimensions need to be developed for measuring managerial performance at the strategic level of the firm.

Another concern is that the Singaporean sample chosen was constrained to responses from CFOs in SMEs in the manufacturing and industrial sectors of the economy. Therefore, large centralized structures were omitted from the analysis by design as well as organizations from the service sector. On the positive side, however, over 95 per cent of the sampled responses came from ethnic Chinese executives. The results of this study could thus be used as a benchmark for subsequent cross-cultural research relying on Hofstede's (1980) taxonomy in the context of changes in management accounting systems. Unfortunately, there is no research in the extant literature that can truly provide a comparative basis for the findings here, either at the cultural level or in terms of the methodological approach.

Finally, not all possible linkages in the Tymon et al. (1998) framework were examined in the present study. For instance, investigating the antecedent linkage from PEU to strategic content (i.e. strategy types) and then on to the MASCs change-performance relationship may yield stronger results. Also, incorporating firm performance as the ultimate effectiveness measure in the overall linkage would be desirable. The latter information was not obtainable in the present study. Nonetheless, future research efforts should attempt to design more complex linkages to capture the antecedent effects and consequence of component change in the management accounting system at the organizational level.

Notwithstanding the foregoing caveats, the results of this study were able to satisfy the contingency fit expectations surrounding the MASCs change-performance relationship at both levels of PEU. This is unique in terms of accounting research using a contingency approach since what is commonly reported in the literature on accounting control systems are outcomes of fit at one extreme of the moderating variable and misfit and the other extreme. As 
indicated though, further research is necessary to validate the present results and extend the method to include other strategic contingencies and, perhaps, scenarios involving multiple fit. The practical benefits of transferring this kind of accounting systems design knowledge to commercial interests are potentially large.

\section{ENDNOTES}

1. The abbreviation 'MASCs' refers to the set of five management accounting system categories, or components, originally developed by Libby and Waterhouse (1996). To avoid confusion, the expression 'MASCs change' is meant to represent the independent variable measure used in the regression models. Also, these interpretations are not to be confused with the use of the term 'MACS' which stands for 'management accounting and control systems'.

2. The hypothesis is stated in the alternate form to facilitate statistical testing that conforms to formulating a contingency hypothesis of the interaction format (Hartman and Moers, 1997, p. 307).

3. Procedures commonly noted in the literature, such as cross-sectional correlation coefficients partitioned on size and early/late responses, yielded no significant differences.

4. The distribution of firms by size is as follows: 100-149 (35); 150-299 (33); 300-499 (12); 500-999 (13); > 1000 (23).

5. The Libby and Waterhouse (1996) study covered the years 1991-1993, a period of 36 months. Williams and Seaman collected change data from January 1995 to end-June 1997, a time span of 30 months. Laitinen (2001) used a 5-year period for the change analysis but the precise starting date was not specified.

6. Controversy admittedly exists in the literature over the multi-dimensional nature of the PEU construct and its measurement (Gerloff, Muir and Bodensteiner, 1991; Milliken, 1987; Otley, 1980; Sharma (2002). Pretesting was conducted on items pertaining to economic turbulence, technological turbulence, legal constraints, and trade barriers. Since acceptable levels of statistical reliability were not obtained, they were omitted from the final questionnaire. Discussions with CFOs during the initial interviews indicated that turbulence of any kind in the external environment was not an issue during the Asian crisis because most macro economic indicators were drifting negatively and not fluctuating wildly (Corsetti, Pesenti and Roubini, 1999). Singaporean firms were more concerned about maintaining their supply chain contacts and inputs from around the region because of their high reliance on imported factor inputs for an export market that accounted for nearly 70 per cent of GDP.

7. One of the more popular scales referenced in the accounting research literature is the performance measure developed by Mahoney, Jerdee and Carroll $(1963 ; 1965)$. It rates performance on eight dimensions plus an overall rating, and is typically applied to middle and upper-level operating managers, but not top executives. Strictly adhered to, the eight dimensions should be independent and should explain 55 per cent or more of the overall rating for the latter to qualify as a valid measure. In a pre-test of this scale for the present study, the staffing, negotiating, and representing dimensions produced no variance and, hence, the scale was discarded in favor of a single question.

8. The reason for including stages 1 and 2 in the analysis was to eliminate any lower-order effects. As Hartmann and Moers (1997, p. 299) succinctly state “... the reason for inclusion of lower-order effects in MRA is to prevent conclusions of the existence of an interaction effect when such an effect is solely due to lower-order effects." Stages 1 and 2, therefore, partial-out any direct main effects.

9. Hartmann and Moers (1997, p. 294) note that "This method is equivalent to the simpler and more direct assessment of the significance of the t-value associated with the coefficient of the product term ...." They also point out that when the moderator variable is a dummy variable with the discrete values 0 and 1 , the interpretation of the significance of the increase in $\mathrm{R}^{2}$ can still be applied. Further, they state (1997, p. 300) "... for tests of an interaction effect using MRA the independent variables need not be ratio-scaled (Southwood, 1978, p. 1167; Arnold and Evans, 1979)."

10. The weak correlations among the MASCs change variables may have occurred because they are essentially sub-dimensions of a larger single construct representing the firm-wide management accounting system. This phenomenon is not unusual in the literature but it is more often associated with various decompositions of performance as a dependent variable (e. g. Perrow, 1970; Brownell, 1982; Daft, 1983).

11. Three median tests using the Kruskal-Wallis Test (a non-parametric analog of one-way ANOVA for detecting differences in location) were conducted and they supported the t-test results. 
12. Hartman and Moers (1999) contend that multicollinearity pertaining to the interaction term in MRA is not a problem. However, the regression models run in stages 1,2 and 4 could be sensitive to this effect. Thus, to test the severity of multicollinearity, Variance Inflation Factors (VIFs) were calculated for all models. Results were well within suggested limits, with the VIFs less than 10 and the average of the VIFs slightly above 1 .

\section{REFERENCES}

1. Arnold, H. J. and Evans, M. G. (1979), Testing multiplicative scales does not require ratio scales, Organizational Behavior and Human Performance, Vol. 24, pp. 41-59.

2. Baiman, S. and Demski, J. S. (1980), Economically optimal performance evaluation and control systems, Supplement to Journal of Accounting Research, Vol. 18, pp.184-228.

3. Berry, M. (1998), Strategic planning in small high tech companies, Long Range Planning, Vol. 31, pp. 45566.

4. Brownell, P. (1982), The role of accounting data in performance evaluation, budgetary participation, organizational effectiveness, Journal of Accounting Research (Spring), pp. 12-27.

5. Brownell, P. and Dunk, A.S. (1991), Task uncertainty and its interaction with budgetary participation and budget emphasis: some methodological issues and empirical investigation, Accounting Organizations and Society, Vol. 16 No. 8, pp. 693-703.

6. Burns, J. and Vaivio, J. (2001), Management accounting change, Management Accounting Research, Vol. 12, pp. 389-402.

7. Chapman, C. S. (1997), Reflections on a contingent view of accounting, Accounting Organizations and Society, Vol. 22 No. 2, pp. 189-205.

8. Chenhall, R. and Morris, D. (1986), The impact of structure, environment, and interdependence on the perceived usefulness of management accounting systems, The Accounting Review, Vol. 61 (January), pp. 1635 .

9. Chenhall, R. and Brownell, P. (1988), The effect of participative budgeting on job satisfaction and performance: Role ambiguity as an intervening variable, Accounting, Organizations and Society, Vol.13 No. 3, pp. 225-34.

10. Child, J. (1972), Organization structure and strategies of control: A replication of the Aston study. Administrative Science Quarterly, Vol. 17, pp. 163-77.

11. Chow, C., Shields, M., and Chan, Y. K. (1991), The effects of management controls and national culture on manufacturing performance: An empirical investigation, Accounting, Organizations and Society, Vol. 16 No. 3, pp. 209-26.

12. Cohn, W. M. and Levinthal, D. (1990), Absorptive capacity: a new perspective on learning and innovation, Administrative Science Quarterly, Vol. 35, pp. 128-52.

13. Corsetti, G., Pesenti, P., and Roubini, N. (1999), What caused the Asian currency crisis?, Japan and the World Economy, Vol. 11, pp. 305-73.

14. Cronbach, L. J. (1951), Coefficient alpha and the internal structure of tests. Psychometrika, Vol. 16 (September), pp. 297-334.

15. Daft, R. L. (1983), Organizational Theory and Design, West Publishing, St. Paul, MN.

16. Demski, J. S. and Feltham, G. A, (1976), Cost determination: A conceptual approach, Iowa State University Press, Ames, Iowa.

17. Dill, W. R. (1962), The impact of environment on organizational development, in Mailack, S and Van Ness, E., Concepts and issues in administrative behavior, Prentice-Hall, Englewood Cliffs, N.J., pp. 29-48.

18. Downey, H. K. (1974), Perceived uncertainty variability: A methodological and exploratory study, Unpublished doctoral dissertation, The Pennsylvania State University.

19. Drazin, R. and Van de Ven, A. H. (1985), Alternative forms of fit in contingency theory, Administrative Science Quarterly, Vol. 30, pp. 514-39.

20. Duncan, R. B. (1972), Characteristics of organizational environments and perceived environmental uncertainty, Administrative Science Quarterly, Vol. 17, pp. 313-27.

21. Dunn and Bradstreet Ltd. (1998), Directory of Singaporean Companies, Singapore. 
22. Ferris, K. R. (1982), Perceived environmental uncertainty, organizational adaptation, and employee performance: A longitudinal study in professional accounting firms, Accounting, Organizations and Society, Vol. 7 No. 1, pp. 13-26.

23. Fitzgerald, L., Johnston, R., Brignall, T. J., Silvestro, R., and Voss, C. (1991), Performance Measurement in Service Businesses, CIMA, London.

24. Frucot, V. and Shearon, W. T. (1991), Budgetary participation, locus of control, and Mexican managerial performance and job satisfaction, The Accounting Review, Vol. 66 No. 1, pp. 80-99.

25. Galbraith, J. (1973), Designing complex organizations, Addison-Wesley, Reading, MA.

26. Galbraith, J. (1977), Organizational design, Addison-Wesley, Reading, MA.

27. Gerloff, E. A., Muir, N. K., and Bodensteiner (1991), Three components of perceived environmental uncertainty and organizational structure: An exploratory study of the effects of aggregation, Journal of Management, Vol. 17, pp. 749-68.

28. Gordon, L. A. and Miller, D. A. (1976), Contingency framework for the design of accounting information systems: Conceptual linkages, Accounting, Organizations and Society, Vol.1 No.1, pp. 59-69.

29. Gosselin, M. (1997), The effect of strategy and organizational structure on the adoption and implementation of activity-based costing, Accounting, Organizations and Society, Vol. 10 No. 2, pp. 153-79.

30. Gordon, L. A. and Narayanan, V. K. (1984), Management accounting systems, perceived environmental and organization structure: An empirical investigation, Accounting, Organizations and Society, Vol. 9 No.1, pp. 33-47.

31. Govindarajan, V. (1984), Appropriateness of accounting data in performance evaluation: An empirical examination of environmental uncertainty as an intervening variable, Accounting, Organization and Society, Vol. 9 No. 2, pp. 125-35.

32. Govindarajan, V. and Gupta, A. K. (198), Linking control systems to business unit strategy: Impact on performance, Accounting, Organizations and Society, Vol. 10 No. 1, pp. 51-66.

33. Granlund, M. (2001), Towards explaining stability in and around management accounting systems, Management Accounting Research, Vol. 12, pp. 141-66.

34. Granlund, M. and Lukka, K. (1998), It's a small world of management accounting practice, Journal of Management Accounting Research, Vol. 10, pp. 153-79.

35. Gray, B. (1990), The enactment of management control systems: A critique of Simons, Accounting, Organizations and Society, Vol. 15 No. 2, pp. 145-8.

36. Gregson, T., Wendell, J., and Aono, J. (1994), Role ambiguity, role conflict, and perceived environmental uncertainty: Are the scales measuring separate constructs for accountants?, Behavioral Research in Accounting, Vol. 6, pp. 144-59.

37. Gresov, C. (1989), Exploring fit and misfit with multiple contingencies, Administrative Science Quarterly, Vol. 34, pp. 431-53.

38. Gresov, C., Drazin, R., and Van de Ven, A. H. (1989), Work-unit task uncertainty, design and morale, Organization Studies, Vol. 10 No. 1, pp. 45-62.

39. Gul, F. (1991), The effects of management accounting systems and environmental uncertainty on small business managements' performance, Accounting and Business Research, Vol. 22, pp. 57-61.

40. Gul, F. and Chia, Y. M. (1994), The effects of management accounting systems, perceived environmental uncertainty and decentralization on managerial performance, Accounting, Organizations and Society, Vol. 19 No. 4/5, pp. 413-26.

41. Hage, J. and Aiken M. (1969), Routine technology, social structure and organization goals, Administrative Science Quarterly, Vol. 14, pp. 366-76.

42. Hall, R. H. (1962), Intra-organizational structural variation: application of the bureaucratic model, Administrative Science Quarterly, Vol. 7, pp. 295-308.

43. Harrison, G. L. (1992), The cross-cultural generalizability of the relation between participation, budget emphasis and job related attitudes, Accounting, Organizations and Society, Vol. 19 No 1, pp. 1-15.

44. Hartmann, F. G. H. and Moers, F. (1999), Testing contingency hypotheses in budgetary research: An evaluation of the use of moderated regression analysis, Accounting, Organizations and Society, Vol. 24 No. 3, pp. 291-315.

45. Heneman, H. G. (1974), Comparisons to self and supervisor ratings of managerial performance, Journal of Applied Psychology, 59, pp. 638-42. 
46. Hofstede, G. H. (1980), Culture's consequences: international differences in work-related values, Sage, Beverly Hills, CA.

47. Hofstede, G. H. (1985), The interaction between national and organizational value systems, Journal of Management Studies, Vol. 23, pp. 347-57.

48. Hofstede, G. H. (1991), Cultures and organizations: Software of the mind, McGraw-Hill, London.

49. Hopwood, A. G. (1987), The archaeology of accounting systems, Accounting, Organizations and Society, Vol. 15, No.3, pp. 207-34.

50. Horngren, C. T. and Sundem, G. L. (1990), Introduction to management accounting, Prentice-Hall, Englewood Cliffs, NJ.

51. Innes, J. and Mitchell, F. (1990), The process of change in management accounting: Some field study evidence, Management Accounting Research, Vol. 1, pp. 3-19.

52. Institute of Management Accountants. (1997), Statements on management 1F draft: Definition and objectives of management accounting, IMA, Montvale, NJ.

53. Khandwalla, P. N. (1972), The effect of different types of competition on the use of management controls, Journal of Accounting Research, Vol. 10, pp.275-85.

54. Khandwalla, P. N. (1977), The design of organizations, Harcourt Brace Jovanivich, New York.

55. Kren, L. (1992), Budgetary participation and managerial performance: The impact of information and environmental volatility, The Accounting Review, Vol. 67, pp. 511-26.

56. Kaplan, R. S. (1985), Accounting lag: The obsolescence of cost accounting systems, in Clark, K. and Lorenze, E., Technology and productivity: The uneasy alliance, Boston, Harvard Business School Press, pp. 195-226.

57. Laitinen, E. K. (2001), Management accounting change in small technology companies: Towards a mathematical model of the technology firm, Management Accounting Research, Vol. 12, pp. 507-41.

58. Lawrence, P. R. and Lorsch, J. W. (1967), Organization and environment, Irwin, Homewood, Ill.

59. Levitt, B. and March, J. G. (1988), Organizational learning, Annual Review of Sociology, Vol. 14, pp. 31940.

60. Libby, T. and Waterhouse, J. H. (1996), Predicting change in management accounting systems, Journal of Managerial Accounting Research, Vol. 8, pp. 137-50.

61. Lorenzi, P., Sims, H. P., Jr., and Slocum, J. W., Jr. (1981), Perceived environmental uncertainty: An individual or environmental attribute, Journal of Management, Vol. 7, pp. 27-41.

62. Luther, R. G. and Longden, S. (2001), Management accounting in companies adapting to structural change and volatility in transition economies: A South African Study, Vol. 12, pp. 299-320.

63. Mahoney, T. A., Jerdee, T. H., and Carroll, S. J. (1963), Development of managerial performance: A research approach, Southwestern Publishing Company, New York.

64. Mahoney, T. A. Jerdee, T. H., and Carroll, S. J. (1965), The jobs of management, Industrial Relations (February), pp. 97-110.

65. Merchant, K. A. (1990), The effects of financial control on data manipulation and myopia, Accounting, Organizations and Society, Vol. 15 No. 3, pp. 297-313.

66. Miles, R. E. and Snow, C. C. (1978), Organizational strategy, structure and process, McGraw-Hill, New York.

67. Miller, D. (1989), The structural and environmental correlates of business strategy, Strategic Management Journal, Vol. 8 No. 1, pp. 55-76.

68. Milliken, F. J. (1987), Three types of perceived environmental uncertainty about the environment: State, effect, and response uncertainty, Academy of Management Review, Vol. 12, pp. 133-43.

69. Nunnally, J. C. (1967), Psychometric theory, McGraw Hill, New York.

70. O'Connor, N. G. (199), The influence of organizational culture on the usefulness of budget participation by Singaporean-Chinese managers, Accounting, Organizations and Society, Vol. 20 No. 5, 383-403.

71. Otley, D. (1980), The contingency theory of management accounting: Achievement and prognosis, Accounting, Organizations and Society, No. 5 No. 4, pp. 413-28.

72. Otley, D. (1999), Performance management: A framework for management control systems research, Management Accounting Research, Vol. 10 No. 4, pp. 363-82.

73. Perrow, C. (197), Organizational analysis: A sociological review, Wadsworth Publishing, Belmont, CA.

74. Porter, M. E. (1980), Competitive Strategy, Free Press, New York. 
75. Prien, E. P. and Liske, R. E. (1962), Assessments of higher-level performance: III. A comparative analysis of supervisor ratings and incumbent self-ratings of job performance, Personnel Psychology (Summer), pp. 18794.

76. Pugh, D. S., Hickson, D. J., Hinings, C. R., and Turner, C. (1968), Dimensions of organizational structure, Administrative Science Quarterly, Vol. 13, pp. 65-105.

77. Pugh, D. S., Hickson, D. J., Hinings, C. R., and Turner, C. (1969), The context of organization structures, Administrative Science Quarterly, Vol. 14, pp. 91-114.

78. Quattrone, P. and Hopper, T. (2001), What does organizational change mean? Speculations on a taken for granted category, Management Accounting Research, Vol. 12, pp. 403-35.

79. Rogers, P. R., Miller, A., and Judge, W. Q. (1999), Using information-processing theory to understand planning/performance relationships in the context of strategy, Strategic Management Journal, Vol. 20 No 6 , pp. 567-77.

80. Sharma, D. H. (2002), The differential effect of environmental dimensionality, size, and structure on budget system characteristics in hotels, Management Accounting Research, Vol. 13, pp. 101-30.

81. Shields, M. D. (1998), Management accounting practices in Europe: A perspective from the states, Management Accounting Research, Vol. 9, pp. 501-13.

82. Shields, J. F. and Shields, M. D. (1998), Antecedents of participative budgeting, Accounting, Organizations and Society, Vol. 23 No. 1, pp. 49-76.

83. Simon, H. A. (1957), Models of man: Social and rational, John Wiley \& Sons, New York.

84. Simons, R. (1987), Accounting control systems and business strategy: An empirical analysis, Accounting, Organizations and Society, Vol. 12 No. 4, pp. 357-74.

85. Southwood, K. E. (1978), Substantive theory and statistical interaction: Five models, American Journal of Sociology, Vol. 83, pp. 1154-1203.

86. Tiessen, P. and Waterhouse, J. H. (1983), Towards a descriptive theory of management accounting, Accounting, Organizations and Society, Vol. 8 No.3, pp. 251-67.

87. Thompson, J. D. (1967), Organizations in action, McGraw-Hill, New York.

88. Tushman, M. L. and Nadler, D. A. (1978), Information processing as an integrating concept in organizational design, Academy of Management Review, Vol. 3, pp. 613-24.

89. Tymon, W. G. Jr., Stout, D. E., and Shaw, K. N. (1998), Critical analysis and recommendations regarding the role of perceived environmental uncertainty in behavioral accounting research, Behavioral Research in Accounting, Vol. 10, pp. 23-46.

90. Waterhouse, J. H. and Tiessen, P. (1978), A contingency framework for management accounting research, Accounting, Organizations and Society, Vol. 3 No. 1, pp. 65-76.

91. Weick, K. E. (1979), The social psychology of organizing, Addison-Wesley, Reading, MA.

92. Williams, J. J. and Seaman, A. E. (2001), Predicting change in management accounting systems: National culture and industry effects, Accounting, Organizations and Society, Vol. 26 No. 5, pp. 443-60.

93. Williams, J. J. and Seaman, A. E. (2002), Management accounting systems change and departmental performance: The influence of managerial information and task uncertainty, Management Accounting Research, Vol. 13, pp. 419-45. 


\section{APPENDIX A: LIST OF MANAGEMENT ACCOUNTING SYSTEM COMPONENTS}

\section{Planning Systems}

1. Budgeting

2. Operations planning (production)

3. Capital budgeting

4. Strategic planning

5. Other planning systems

\section{Controlling Systems}

6. Individual or team-based performance measurement

7. Organizational performance measurement

8. Measurement of performance in terms of quality

9. Measurement of performance in terms of customer satisfaction

10. Other performance measures

\section{Costing Systems}

11. Direct allocation of manufacturing overhead

12. Direct allocation of marketing costs

13. Direct allocation of other overhead

14. Internal (dept. or divisional) product transfers

15. Other costing systems

Directing Systems

16. Reward systems - bonuses

17. Reward systems - pay-for-performance plans

18. Other reward systems

Decision Making Systems

19. Information reported more frequently

20. Use of more nonfinancial measures

21. Information reported more broadly

22. Other changes to reporting systems

23. Other changes to systems that do not appear on this list 
Table I

Descriptive Statistics $(\mathbf{n}=116)$

\begin{tabular}{ccccc} 
Variable & Mean & $\begin{array}{c}\text { Descriptive Statistics }(\mathbf{n = 1 1 6}) \\
\text { S. D. }\end{array}$ & $\begin{array}{c}\text { Theoretical } \\
\text { Range }\end{array}$ & $\begin{array}{c}\text { Actual } \\
\text { Range }\end{array}$ \\
\hline PERF & & 0.991 & $1-7$ & $1-7$ \\
PLAN & 4.826 & 1.206 & - & $0-5$ \\
CON & 0.914 & 1.398 & - & $0-5$ \\
COST & 0.974 & 0.779 & - & $0-5$ \\
DIR & 0.405 & 0.900 & - & $0-3$ \\
DM & 0.620 & 1.343 & $5-25$ & $0-5$ \\
PEU & 1.069 & 4.186 & $-5-25$ \\
\hline
\end{tabular}

Variable definitions: PERF $=$ managerial performance; PLAN $=$ planning systems changes; CON $=$ controlling systems changes; COST = costing systems changes; DIR = directing; systems changes; $\mathrm{DM}=$ decision making systems changes; $\mathrm{PEU}=$ perceived environmental uncertainty measured as a continuous variable.

Table II

\begin{tabular}{|c|c|c|c|c|c|c|}
\hline \multicolumn{7}{|c|}{ Pearson Correlation Matrix $(n=116)$} \\
\hline Variable & 1 & 2 & 3 & 4 & 5 & 6 \\
\hline \multicolumn{7}{|l|}{ 1. PERF } \\
\hline 2. PLAN & 0.045 & & & & & \\
\hline 3. $\mathrm{CON}$ & 0.047 & $0.391 *$ & & & & \\
\hline 4. $\operatorname{COST}$ & -0.126 & $0.361 *$ & $0.368^{*}$ & & & \\
\hline 5. DIR & -0.058 & $0.370^{*}$ & $0.386^{*}$ & 0.076 & & \\
\hline 6. DM & 0.158 & $0.283^{*}$ & $0.408^{*}$ & $0.278^{*}$ & $0.259 *$ & \\
\hline 7. PEU & 0.068 & 0.139 & $0.253^{*}$ & 0.136 & -0.068 & 0.133 \\
\hline
\end{tabular}

Variable definitions: PERF = managerial performance; PLAN = planning systems changes; CON = controlling systems changes; COST $=$ costing systems changes; DIR = directing systems changes; $\mathrm{DM}=$ decision making systems changes; $\mathrm{PEU}=$ perceived environmental uncertainty measured as a continuous variable.

$* \mathrm{p}<0.05$.

Table III

Profile Of Systems Changes For PEU Subgroups

\begin{tabular}{lcccccc} 
Variable & \multicolumn{2}{c}{$\begin{array}{c}\text { Low PEU }(\mathbf{n}=\mathbf{6 2}) \\
\text { Changes }\end{array}$} & Mean & $\begin{array}{c}\text { High PEU }(\mathbf{n}=\mathbf{5 4}) \\
\text { Changes }\end{array}$ & $\begin{array}{c}\text { Total } \\
\text { Mean }\end{array}$ & $\begin{array}{c}\text { Percentage of } \\
\text { changes }\end{array}$ \\
\hline PLAN & 47 & 0.758 & 59 & 1.109 & 106 & 23 \\
CON & 40 & 0.645 & 73 & 1.351 & 113 & 25 \\
COST & 19 & 0.307 & 28 & 0.518 & 47 & 10 \\
DIR & 42 & 0.677 & 30 & 0.556 & 72 & 15 \\
DM & 56 & 0.903 & 68 & 1.259 & 124 & 27 \\
Total & 204 & 3.290 & 258 & 4.777 & 462 & 100 \\
\hline
\end{tabular}

Variable definitions: PLAN = planning systems changes; $\mathrm{CON}=$ controlling systems changes; COST = costing systems changes; $\mathrm{DIR}=$ directing systems changes; $\mathrm{DM}=$ decision making systems changes; $\mathrm{PEU}=$ perceived environmental uncertainty. 
Table IV

Regression Results For Stages 1 Through $4^{\text {a }}$

\begin{tabular}{|c|c|c|c|c|c|c|}
\hline Variable & $\begin{array}{c}\text { Stage } 1 \\
\text { (Eq. 1) }\end{array}$ & $\begin{array}{c}\text { Stage } 2 \\
\text { (Eq. 2) }\end{array}$ & $\begin{array}{c}\text { Stage } 3 \\
\text { (Eq. 3) }\end{array}$ & $\begin{array}{c}\text { Stage } 4 \\
\text { Low PEU }\end{array}$ & High PEU & F-test diff. \\
\hline PLAN & $\begin{array}{c}0.103 \\
(0.961)\end{array}$ & $\begin{array}{c}0.100 \\
(0.924)\end{array}$ & $\begin{array}{c}0.280 \\
(1.839)\end{array}$ & $\begin{array}{c}0.257 \\
(1.926)^{*}\end{array}$ & $\begin{array}{c}-0.104 \\
(-0.637)\end{array}$ & $13.661 * * *$ \\
\hline $\mathrm{CON}$ & $\begin{array}{c}0.070 \\
(0.621)\end{array}$ & $\begin{array}{c}0.060 \\
(0.521)\end{array}$ & $\begin{array}{c}0.211 \\
(1.158)\end{array}$ & $\begin{array}{c}0.168 \\
(1.213)\end{array}$ & $\begin{array}{c}0.191 \\
(0.933)\end{array}$ & 1.214 \\
\hline COST & $\begin{array}{c}-0.236 \\
(-2.266) * *\end{array}$ & $\begin{array}{c}-0.236 \\
(-2.257)^{* *}\end{array}$ & $\begin{array}{c}-0.482 \\
(-2.919)^{* *}\end{array}$ & $\begin{array}{c}-0.412 \\
(-3.056)^{* *}\end{array}$ & $\begin{array}{c}-0.016 \\
(-0.104)\end{array}$ & $17.057 * * *$ \\
\hline DIR & $\begin{array}{c}-0.160 \\
(-1.528)\end{array}$ & $\begin{array}{c}-0.152 \\
(-1.420)\end{array}$ & $\begin{array}{c}0.016 \\
(0.123)\end{array}$ & $\begin{array}{c}-0.017 \\
(-0.128)\end{array}$ & $\begin{array}{c}-0.415 \\
(-2.087)^{* *}\end{array}$ & $14.412 * * *$ \\
\hline DM & $\begin{array}{c}0.207 \\
(2.021)^{*}\end{array}$ & $\begin{array}{c}0.205 \\
(1.995)^{*}\end{array}$ & $\begin{array}{c}0.063 \\
(0.403)\end{array}$ & $\begin{array}{c}0.061 \\
(0.442)\end{array}$ & $\begin{array}{c}0.296 \\
(2.054)^{* *}\end{array}$ & $13.208 * * *$ \\
\hline PEU & & $\begin{array}{c}0.033 \\
(0.340)\end{array}$ & $\begin{array}{c}0.095 \\
(0.726)\end{array}$ & & & \\
\hline PEU 5 PLAN & & & $\begin{array}{c}-0.332 \\
(-1.790)^{*}\end{array}$ & & & \\
\hline PEU 5 CON & & & $\begin{array}{c}-0.037 \\
(-0.158)\end{array}$ & & & \\
\hline PEU 5 COST & & & $\begin{array}{c}0.400 \\
(2.231)^{* *}\end{array}$ & & & \\
\hline PEU 5 DIR & & & $\begin{array}{c}-0.314 \\
(-1.785)^{*}\end{array}$ & & & \\
\hline PEU 5 DM & & & $\begin{array}{c}0.196 \\
(1.107)\end{array}$ & & & \\
\hline $\mathrm{N}$ & 116 & 116 & 116 & 62 & 54 & $\mathrm{n} / \mathrm{a}$ \\
\hline $\mathrm{R}^{2}$ & 0.080 & 0.081 & 0.200 & 0.203 & 0.191 & $\mathrm{n} / \mathrm{a}$ \\
\hline Adj. $\mathrm{R}^{2}$ & 0.038 & 0.030 & 0.116 & 0.132 & 0.106 & $\mathrm{n} / \mathrm{a}$ \\
\hline $\mathrm{F}$ & 1.890 & 1.591 & $2.369 * *$ & $2.849 * *$ & $2.261 * *$ & $\mathrm{n} / \mathrm{a}$ \\
\hline
\end{tabular}

Variable definitions: PERF = managerial performance; PLAN = planning systems changes; CON = controlling systems changes; COST = costing systems changes; DIR = directing systems changes; DM = decision making systems changes; PEU = a dummy variable equal to zero if perceived environmental uncertainty is low, one if perceived environmental uncertainty is high.

${ }^{\mathrm{a}} \mathrm{Standardized} \mathrm{regression} \mathrm{coefficients} \mathrm{are} \mathrm{reported} \mathrm{in} \mathrm{parentheses.}$

$* \mathrm{p}<0.10$.

$* * \mathrm{p}<0.05$.

$* * * \mathrm{p}<0.01$. 